\title{
Lipid Profile and Antioxidant Activity of Macadamia Nuts (Macadamia integrifolia) Cultivated in Venezuela
}

\author{
Alejandra Rengel ${ }^{1}$, Elevina Pérez ${ }^{1}$, George Piombo르, Julien Ricci ${ }^{3}$, Adrien Servent ${ }^{3}$, \\ María Soledad Tapia ${ }^{1}$, Olivier Gibert ${ }^{3}$, Didier Montet $^{3}$ \\ ${ }^{1}$ Instituto de Ciencia y Tecnología de Alimentos, Facultad de Ciencias, Universidad Central de Venezuela, \\ Caracas, Venezuela \\ ${ }^{2}$ Cirad, UMR late, Campus de la Gaillarde, 2 place Pierre Viala, Montpellier, France \\ ${ }^{3}$ Cirad, UMR 95 Qualisud, TA B-95/16, 73, rue Jean-François Breton, Montpellier, France \\ Email: ars733@hotmail.com
}

Received 19 July 2015; accepted 20 November 2015; published 24 November 2015

Copyright (C) 2015 by authors and Scientific Research Publishing Inc.

This work is licensed under the Creative Commons Attribution International License (CC BY).

http://creativecommons.org/licenses/by/4.0/

c. (i) Open Access

\begin{abstract}
Macadamia nuts (Macadamia integrifolia) grown in Venezuela have showed an average total fat content of $70 \%$. Oleic acid (18:1) was the main monounsaturated fatty acid (MUFA) (51.3\%), followed by palmitoleic acid (16:1, 22.6\%). The content of polyunsaturated fatty acids (PUFAs), C18:2 and C18:3 represented 5.4\%. Thus, MUFAs and PUFAs together constituted more than 80\% of the total fatty acids present. Trans-vaccenic acid was also present (3\%). As regards to other phytochemical compounds, tocopherols and tocotrienols were not found in the sample, but the presence of squalene was detected. The antioxidant activity (44.2\%) of the extract was produced by the phytochemicals present.
\end{abstract}

\section{Keywords}

Lipids, Antioxidant Activity, Fatty Acids, Macadamia Nut, Phytochemical Compounds

\section{Introduction}

Nuts, seeds and dried fruits have natural functional properties which can be used to develop nutritional or active foods [1]. In addition, nuts give a feeling of satiety, whilst providing high amounts of energy, minerals and vitamins that are of great interest in the development of special diets [2].

The consumption of nuts, either as seeds or oils, has been associated with a decrease in cardiovascular diseases, diabetes and obesity [3]. Nuts (walnuts, macadamia nuts, almonds, pistachios, etc.) are composed mainly of 
monounsaturated (40\% - 60\%) and saturated (7\%) fatty acids, fiber, potassium, magnesium, copper, vitamin E and arginine [4]. Because of this, the regular addition of walnuts, macadamia nuts, almonds and peanuts as part of a healthy diet can result in a significant reduction of cholesterol levels in the blood. Recently the FDA has recognized dried fruits and nuts as "heart healthy" foods [1].

Macadamia nuts (Figure 1), which is considered to be one on the highest ranking nuts in the world for their high content and quality of their oil, are native from Australia. Australia is also the main commercial grower, producing around 40,000 tons of Macadamia nuts per year. Macadamia nuts are also grown commercially in some South American countries, such as Brazil, Costa Rica and Bolivia, as well as in Hawaii, New Zealand and Africa, with a total world annual production of 100,000 tons [5]. Minor producers of these nuts can also be found in: Bolivia, China, El Salvador, Fiji, Philippines, Indonesia, Mexico, New Zealand, Paraguay, Peru, Thailand, Tanzania, Venezuela, Zimbabwe, Rhodesia and Colombia. In Venezuela, most of the current production is in Lara state, (8.5 - 9 tons/year), where the macadamia trees are used to provide shade in coffee plantations [6].

The content of fat in these nuts represents more than $70 \%$ of their weight, however their sodium and saturated fat levels are low. Macadamia nut oil contains the highest percentage of unsaturated fats varying from $80 \%$ to 81.8\% [7], compared to other oils, such as olive oil (74\%) [2] and other nuts (51.6\% - 67.7\%) [8]. Macadamia nuts contain the highest amounts of monounsaturated fatty acids (MUFAs), predominantly oleic (60\%) and palmitoleic (20\%) acids of any known food [7]. Diets that contain foods with high content in MUFAs will reduce the plasma low density lipoprotein (LDL), and cholesterol levels, thus decreasing the risk of cardiovascular disease [9]. This cardio protective effect is associated with the high percentage of unsaturated fatty acids present [9].

Macadamia nuts are also rich in essential trace elements such as: calcium, iron, phosphorus, magnesium and potassium, and vitamins such as thiamine (B1), riboflavin (B2), retinol (A1), and niacin (B3).

In addition to the nutritional characteristics of macadamia nuts, some authors have reported antioxidant properties conferred by the presence of tocopherols, tocotrienols, and squalene [10]. Antioxidants are a group of molecules recognized for their ability to neutralize free radicals, and are thus considered an alternative for combating deficiencies associated with oxidative stress, such as cardiovascular and rheumatic diseases and even aging.

Squalene, which has been shown to decrease oxygen levels and prevent lipid peroxidation [10], is abundant in olive oil and quinoa and has also been found in small quantities $(185 \mu \mathrm{g} / \mathrm{g})$ in macadamia nuts [10].

The aim of this study was to quantify total fat and lipid profile, identify and quantify specific phytochemicals (tocopherols, tocotrienols, and squalene) and determine the antioxidant capacity of macadamia nuts cultivated in Venezuela.

\section{Materials and Methods}

\subsection{Materials}

Dried macadamia nuts were obtained from the Production and Agricultural Extension Unit "Las Lomas", Villanueva village, Hilario Luna and Luna parish, Moran municipality, Lara state, Venezuela. A total of six kg of nuts were harvested between April and November 2012. The collected nuts were stored at a temperature of $4^{\circ} \mathrm{C}$ until analysis.

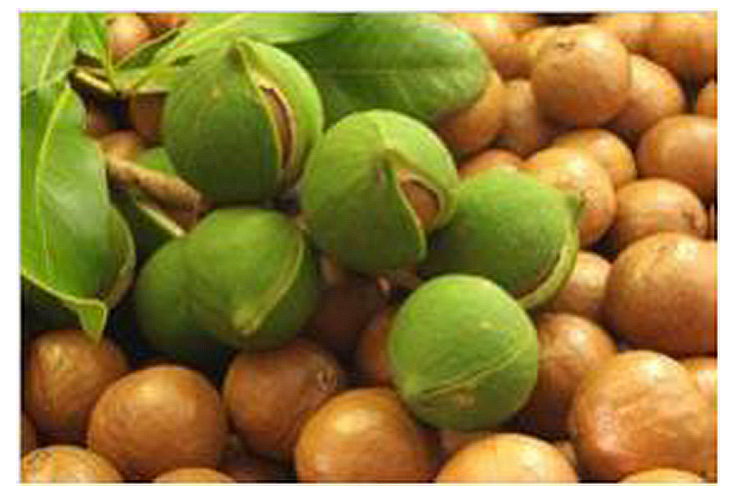

Figure 1. Nut of Macadamia integrifolia. 


\subsection{Methods}

\subsubsection{Determination of Crude Fat Content and Extraction of Lipids}

Total lipid content (extracted in duplicate) was determined using the Soxhlet method [11]. The resulting oil was stored at $-20^{\circ} \mathrm{C}$ for the subsequent determination of tocopherols, tocotrienols and squalene.

\subsubsection{Analysis of Identity Parameters of Macadamia Nut Oil}

Specific gravity of was measured by using a pycnometer. Three $10-\mathrm{mL}$ Fisher pycnometers, and a water bath at constant-temperature with a Micrc-set thermoregulator were used in the procedures for the specific gravity determination in, accordance with ASTM D 369 and 445 ASTM [12], respectively. The pycnometers were filled with the macadamia oil sample at a $2^{\circ} \mathrm{C} \pm 1{ }^{\circ} \mathrm{C}$ temperature below the bath temperature. It was assured to prevent direct contact between the bath fluid and the capillary opening of the pycnometer neck. This assembly was secured to the bath cover and clip and immersed inside the bath, the procedures in the ASTM standard test methods D 891 (test Method B) and D 369 [12] were followed for the density determinations and the following formula was used:

$$
\text { Specific gravity }=\frac{(\text { Weight pycnometer }+ \text { sample })-\text { Weight of pycnometer }}{(\text { Weight pycnometer }+ \text { water })-\text { Weight of pycnometer }}
$$

The determination of the refractive index (at $20^{\circ} \mathrm{C} \pm 0.1^{\circ} \mathrm{C}$ ) was done putting a few drops of macadamia oil with a pipette on the lower prism Abbe refractometer at $20^{\circ} \mathrm{C}$, following the procedures of Cocks and Van Rede [13].

The determination of the iodine value is based on the addition of iodine to the double bonds of unsaturated fatty acids. The result is given as $\mathrm{g} \mathrm{I}_{2}$ consumed by $100 \mathrm{~g}$ sample and is a measure for the unsaturation of oil. To determine the index of iodine: iodine index was calculated from the fatty acid composition, according to Standard AOCS [14] method Cd 1c-85. The result was expressed in g of iodine/100 grams oil. The equation used was as follows:

Iodine value $=(\%$ palmitoleic acid $\times 0.95)+(\%$ of oleic acid $\times 0.86)+(\%$ linoleic acid $\times 1732)+(\%$ linolenic acid $\times 2616$ ).

Saponification value is expressed by potassium hydroxide in mg required to saponify one (1) gram of fat. Measurement of saponification index was performed by using the formula [15]:

Saponification index $=56,000$ /average PM +12.67

Where: PM average $=$ average of molecular weight of fatty acids.

\subsubsection{Determination of the Fatty acid Profile by Gas Chromatography (GC)}

The fraction of lipids evaluated was obtained following the French ISO Norm 5509 (1977) [16], which describe a method for the preparation and analysis of fatty acids methyl esters from fat bodies of animal and plant origin.

The preparation of the methyl esters was realized as follows: 2 to 3 drops of the fat sample and 2 or 3 pieces of $5 \mathrm{~mm}$ of pumice and $3 \mathrm{ml}$ of $0.2 \mathrm{~N}$ sodium methylate were placed in a round-bottom flask (10 cm diameter). The round-bottom flask was set up with a saponification cane to be heated under reflux for 10 minutes, with 3 $\mathrm{mL}$ of hydrochloric acid in $2 \%$ of methanol, which was added by the top of the cane, up to observing the discoloration of the phenolphthalein. Then sample is again heated under reflux for 10 minutes. After cooling the sample at room temperature; $8 \mathrm{ml}$ hexane, $10 \mathrm{ml}$ of distilled water were added. Subsequently, the assessments through gas chromatography were compared to a standard, which allowed to displaying the type and quantity of fatty acid in sample.

Gas chromatography of the fatty acids methyl esters (FAMEs), was performed according to ISO standard [17] on a HP 6890 GC System with autosampler. The column was a highly polar SGE Capillary BPX 70 of $60 \mathrm{~m}$ length, $0.22 \mathrm{~mm}$ internal diameter with $70 \%$ Cyanopropyl (equiv.) polysilphenylene-siloxane phase. Gradient oven temperature program was from $160^{\circ} \mathrm{C}$ to $190^{\circ} \mathrm{C}$, heating rate: $2.5^{\circ} \mathrm{C} / \mathrm{min}$; carrier gas: helium, flow rate 0.6 $\mathrm{mL} / \mathrm{min}$; Temperature of split-splitless injector $240^{\circ} \mathrm{C}$; Flame ionization detector (FID); flame gas: $\mathrm{H} 2$; software: HP Chemstation v. 3.11; sample injection: $1 \mu \mathrm{L}$ in iso-octane.

FAMEs were identified by comparing their relative and absolute retention times to those of authentic standards of FAMEs obtained from Sigma Chemical Co. All quantifications were done by a built-in data-handling program provided by the manufacturer of the gas chromatograph. The FA composition was reported as a relative 
percentage of the total peak area.

\subsubsection{Determination of the Lipid Profile by Thin Layer (TLC) Chromatography}

Thin layer chromatography was carried out according to the technique described by Tuckey and Stevenson [18]. The extracted lipid fraction was applied 4 times in small drops to the upper part of a 0.25 mm silica gel plate. TLC was performed by placing the inverted plate in a tank containing hexane/diethyl ether/acetic acid (75/25/1, $\mathrm{v} / \mathrm{v} / \mathrm{v}$ ). When the solvent front was $1 \mathrm{~cm}$ below the upper edge of the plate (approximately 10 min), plate was removed, sprayed with copper acetate saturated in water $/ \mathrm{H}_{3} \mathrm{PO}_{4}(50 / 50 \mathrm{v} / \mathrm{v})$ and then dried in an oven at $180^{\circ} \mathrm{C}$ for $10 \mathrm{~min}$. The components were then carbonized and identified by comparison of their migration distance on the plate, and compared with reference molecules.

Chromatography was performed with 1,2 , and $5 \mu \mathrm{L}$ of sample, to observe the distribution of mono, di and triglycerides and fatty acids within the lipid profile.

\subsubsection{Determination of Tocopherols and Tocotrienols by High Performance Liquid Chromatography (HPLC)}

The content of tocopherols and tocotrienols was evaluated by HPLC following the methodology described in the international standard ISO-FDIS 9936 [19]. Samples were diluted in solvent before injection into the HPLC column as follows.

The oil used to do the determination, was obtained by using the Soxhlet's method. 2 g of dehydrated and crushed macadamia nut were weighted, and placed in a cellulose thimble in an extraction chamber, which is placed on top of a collecting flask beneath a reflux condenser. A suitable solvent (hexane) is added to the flask, and the set up is heated under reflux, when a certain level of condensed solvent has accumulated in the thimble, it is siphoned into the flask beneath. After extraction the solvent is removed, by means of a rotary evaporator, yielding the extracted compound (test sample). The non-soluble portion of the extracted solid remains in the thimble, and is discarded.

Briefly, $2.0 \pm 0.1 \mathrm{~g}$ of the test sample was weighed and placed in a $25 \mathrm{~mL}$ vial added with $\mathrm{X}$ mL hexane and the solution were stirred to dissolve the residue. Once dissolved, the vial was filled with the same solvent. Posteriorly, $20 \mu \mathrm{L}$ of the test solution was injected into the column and the tocopherols were identified by comparison with the chromatogram of a standard solution. The tocopherols were then quantified using the calibration factors determined from the standard solutions.

\subsubsection{Determination of Squalene}

Squalene was detected by thin layer chromatography using silica gel 60G. The eluents used were: 50\% of chloroform/methanol/water 60/30/51 (v/v/v) and 50\% of hexane/diethyl ether/formic acid at 80/20/1 ratio (v/v/v). The plates were sprayed with phosphomolybdic acid at $1.3 \% / \mathrm{H}_{2} \mathrm{SO}_{4} 10 \%$ in $100 \mathrm{~mL}$ ethanol. The plates were then dried in an oven at $180^{\circ} \mathrm{C}$ for $10 \mathrm{~min}$. The components were carbonized and identified by comparing the migration distance along the plate with standard squalene values.

\subsubsection{Determination of Antioxidant Activity}

The antioxidant capacity of the sample was determined as the radical trapping capacity using the free radical technique 2, 2-Diphenyl-1-picrylhydrazyl (DPPH), following the methodology proposed by Brand-Williams et al. [20]: $2.9 \mathrm{~mL}$ of DPPH (4\% concentration) was mixed with $0.1 \mathrm{~mL}$ of the sample at different concentrations, and spectrophotometric measurements were made at $515 \mathrm{~nm}$. A standard sample was prepared by diluting $1 \mathrm{~g}$ of ground macadamia nut in $10 \mathrm{~mL}$ of methanol. The concentration ratios tested based on this solution were: 1:4, $1: 5,1: 6,1: 7$ and $1: 8$.

\section{Results and Discussion}

\subsection{Total Crude Fat Content}

The analyzed nuts contained an average of 70\% oil (dry matter), which is similar to other nuts such as pine nuts (68\% - 75\%), hazelnuts (70\% - 72\%), walnuts (63\% - 70\%) [21]-[23] and Brazil nuts (67\%) [24]. Similar results can be found in the literature for macadamia nuts of other origins. Kaijser et al. [25] reported between 69\% - 78\% of oil content in four cultivars of macadamia in New Zealand, while Maguire et al. [10] reported 59\% of oil in 
fresh macadamia nuts from Ireland. Koaze et al. [26], reported a range between $60 \%$ and $69.4 \%$ of fat from dehydrated nuts collected between April and August in Nairobi and central Kenya, noting that this increased towards the end of the harvest season. Nuts in our study were collected between the months of April and November 2012.

\subsection{Chemical and Physical Characteristics of Crude Macadamia Nut Oil}

Table 1 is compiling the chemical and physical characteristics of the macadamia oil, determined on the freshly collected nut, and compared with several vegetable oils. As can be seen in Table 1, the specific gravity found at the macadamia oil of $0.9213 \mathrm{~g} / \mathrm{ml}$ is slightly different from those found by Carvajal and Bedoya [27] of 0.9080 $\mathrm{g} / \mathrm{mL}$, for oil from Macadamia nut of specie tetraphylla, and is also different to those values of other vegetable oils. The specific gravity is an important criterion of identity for edible oils, the value reported in this research, could be considered for the oil from Macadamia integrifolia nut.

In this study the oil from Macadamia integrifolia nuts showed a refractive index of 1.4679, which bears some similarity to the results of Winston and Shaw [28] for M. intregrifolia that varies from 1.4657 to 1.4681, and Carvajal and Bedoya [27] of 1.4607 for M. tetraphylla.

The average iodine index for macadamia nut oil, of the study, was determined $61.4 \mathrm{cg} / \mathrm{g}$. Based on the classification of oils, by this standard, this oil is a non-drying oil (below 100 Iodine Index) (Table 1), which predicts a low percentage of polyunsaturated fatty acids, which is confirmed by its composition obtained by GC-MS. In the above classification there are some oils such as; olive oil, castor and almond oils. The value here found for M. integrifolia is lower than those shown by the oil of peanut oil and cashew nut.

The saponification index found for M. intergrifolia oil showed a mean value of $214.1 \mathrm{mg} \mathrm{KOH} / \mathrm{g}$; this value differed from that reported for M. tetraphylla oil $197.3 \mathrm{mg} \mathrm{KOH} / \mathrm{g}$, which is similar to those reported for walnut oil (Juglans Regia) of 189 - $193 \mathrm{mg} \mathrm{KOH/g} \mathrm{[28]-[30]} \mathrm{(Table} \mathrm{1).} \mathrm{The} \mathrm{determination} \mathrm{of} \mathrm{this} \mathrm{parameter} \mathrm{showed}$ that the oil of $M$. integrifolia species had a high proportion of short-chain fatty acids, characteristic property of oils like olive oil (184 - $196 \mathrm{mg} \mathrm{KOH/g}$ ); as well as oils from other oilseeds such as sesame, sunflower and peanuts (Table 1).

The characterization of the oil was carried out immediately after the oil extraction process. It was why the evaluation of the indices of peroxide and acid were omitted. These indices may indicate deterioration by oxidative degradation or an hydrolysis by lipases respectively during the extraction process.

Unlike other similar studies, in this work was studied and summarized the identity of the oil of nut of macadamia, not only by considering type, quality and importance of its lipids, but evaluating its functional

Table 1. Analysis of identity profile of Macadamia integrifolia oil, compared to different vegetables oil.

\begin{tabular}{ccccc}
\hline Oil type & Specific gravity $(\mathrm{g} / \mathrm{mL})$ & Refractive index, $\eta 20 \mathrm{D}$ & Saponification Index (mg KOH/g) & Iodine index (g/100g) \\
\hline Coconut $^{1}$ & $0.917-0.919 \mathrm{~d}$ & $1.4480-1.4500 \mathrm{~b}$ & $250-264 \mathrm{f}$ & $7.5-10.5 \mathrm{a}$ \\
Sesame seed $^{1}$ & $0.916-0.921 \mathrm{~d}$ & $1.4700-1.4740 \mathrm{bc}$ & $188-195 \mathrm{bcd}$ & $103-188 \mathrm{e}$ \\
Peanut $^{1}$ & $0.909-0.915 \mathrm{bcd}$ & $1.4670-1.4700 \mathrm{bc}$ & $195-205 \mathrm{~d}$ & $80-100 \mathrm{bcd}$ \\
Sunflower $^{1}$ & $0.915-0.918 \mathrm{~cd}$ & $1.4710-1.4750 \mathrm{bc}$ & $248-254 \mathrm{f}$ & $125-136 \mathrm{de}$ \\
Palm $^{1}$ & $0.900-0.913 \mathrm{ab}$ & $1.4990-1.4520 \mathrm{c}$ & $176-182 \mathrm{a}$ & $71.4 \mathrm{~b}$ \\
Cahsew $^{2}$ & $0.8984 \mathrm{a}$ & $1.4721 \mathrm{bc}$ & $181.8 \mathrm{ab}$ & $80 \mathrm{bc}$ \\
Olive $^{3}$ & $0.910-0.916 \mathrm{bcd}$ & $1.4677-1.4705 \mathrm{bc}$ & $182-193 \mathrm{abc}$ & $115-124 \mathrm{cde}$ \\
Corn $^{4}$ & $0.914-0.921 \mathrm{~cd}$ & $1.4701-1.4710 \mathrm{bc}$ & $187-193 \mathrm{abcd}$ & $125-140 \mathrm{e}$ \\
Soy $^{4}$ & $0.915-0.925 \mathrm{~d}$ & $1.4704-1.4744 \mathrm{bc}$ & $187-197 \mathrm{bcd}$ & $140-150 \mathrm{e}$ \\
Walnut $^{5}$ & - & $0.6500-0.6750 \mathrm{a}$ & $193-196 \mathrm{~cd}$ & $197.3 \mathrm{f}$ \\
Macadamia nut & & & & $61.38 \mathrm{~b}$
\end{tabular}

${ }^{1}$ Jurado and Muñoz (2009) [50]. ${ }^{2}$ Mujica et al., (2010) [51]. ${ }^{3}$ Codexstan (1989) [52]. ${ }^{4}$ Bailey (1951) [53]. ${ }^{5}$ Weston and Fryer (1920) [29]. ${ }^{6}$ Carvajal and Bedolla, (2010) (M. tetraphylla) [27], and Wiston and Shaw (1943) (M. integrifolia) [28]. ${ }^{7}$ Data of this researching (M. integrifolia). Different letters in the same column, indicate statistically significant differences $(\mathrm{p} \leq 0.05)$. 
characteristics, but also the presence of tocopherols and tocotrienols (Vitamin E), its antioxidant capacity, and revealing the presence of squalene. Moreover, the significance and novelty of this study lies, as can be seen in Table 1 which is comparing data of the analysis of identity for M. integrifolia oil from Venezuela to those found in Colombia (27) and Hawaii (28), that they are showing lightly differences among them, which could be also observed in its fatty acid profile. These differences can be attributed to environmental differences, and it is relevant to characterize the $M$. Integrifolia from different localities, before it will be used.

\subsection{Determination of the Fatty Acid Profile by GC}

Table 2 and Figure 2 show the fatty acid profile of macadamia nut oils. It is important to highlight the high content of monounsaturated fatty acids (MUFAs) representing $77.5 \%$ of total fat content (Table 3) with 51.3\% palmitoleic acid and $22.6 \%$ oleic acid. The oil contained $4.8 \%$ polyunsaturated (PUFA) including $2.4 \%$ linoleic acid and $2.4 \% \alpha$-linolenic acid (Table 3).

Oleic acid (cis 18:1 n-9) is present in animal fats and vegetable oils and has been shown to protect against cardiovascular diseases, since it reduces the levels of total cholesterol and low density lipoproteins. Both oleic acid and polyphenols, presents in olive oil, have been shown to increase high-density lipoprotein (HDL) cholesterol, and to protect HDL from oxidation, a phenomenon associated with a low cholesterol efflux from cells [31].

Table 2. Fatty acid profile of Macadamia integrifolia oil determined by CG.

\begin{tabular}{cc}
\hline Fatty acids & Percentage of total fats \\
\hline C 12:0 Lauric & 0.1 \\
C 16:0 Palmitic & $\mathbf{9 . 4}$ \\
C 16:1 Palmitoleic (n-7) & $\mathbf{2 2 . 6}$ \\
C 17:0 Margaric & 0.3 \\
C 17:0 Iso Margaric & 0.1 \\
C 18:0 Stearic & $\mathbf{3 . 0}$ \\
C 18:1 (n-9) Oleic & $\mathbf{5 1 . 3}$ \\
C 18:1 (n-7) Trans-vaccenic & $\mathbf{3 . 0}$ \\
C 18:2 (n-6) Linoleic & $\mathbf{2 . 4}$ \\
C 20:0 Arachidic & $\mathbf{2 . 5}$ \\
C 18:3 (n-3) $\boldsymbol{\alpha}$-linolenic & $\mathbf{2 . 4}$ \\
C 20:1 (n-9) & 0.3 \\
C 22:0 Behenic & 0.8 \\
C 22:1 (n-9) Erucic & 0.3 \\
C 24:0 Arachidonic & 0.3 \\
Other & 1.2 \\
Total & 100 \\
\hline
\end{tabular}

Table 3. Saturation profile of fatty acids in Macadamia integrifolia oil.

\begin{tabular}{cc}
\hline Fatty acid type & Percentage of total fats \\
\hline Saturated fatty acids & 16.5 \\
Monounsaturated fatty acids (MUFAs) & 77.5 \\
Polyunsaturated fatty acids (PUFAs) & 4.8 \\
Others & 1.2 \\
Total & 100 \\
\hline
\end{tabular}




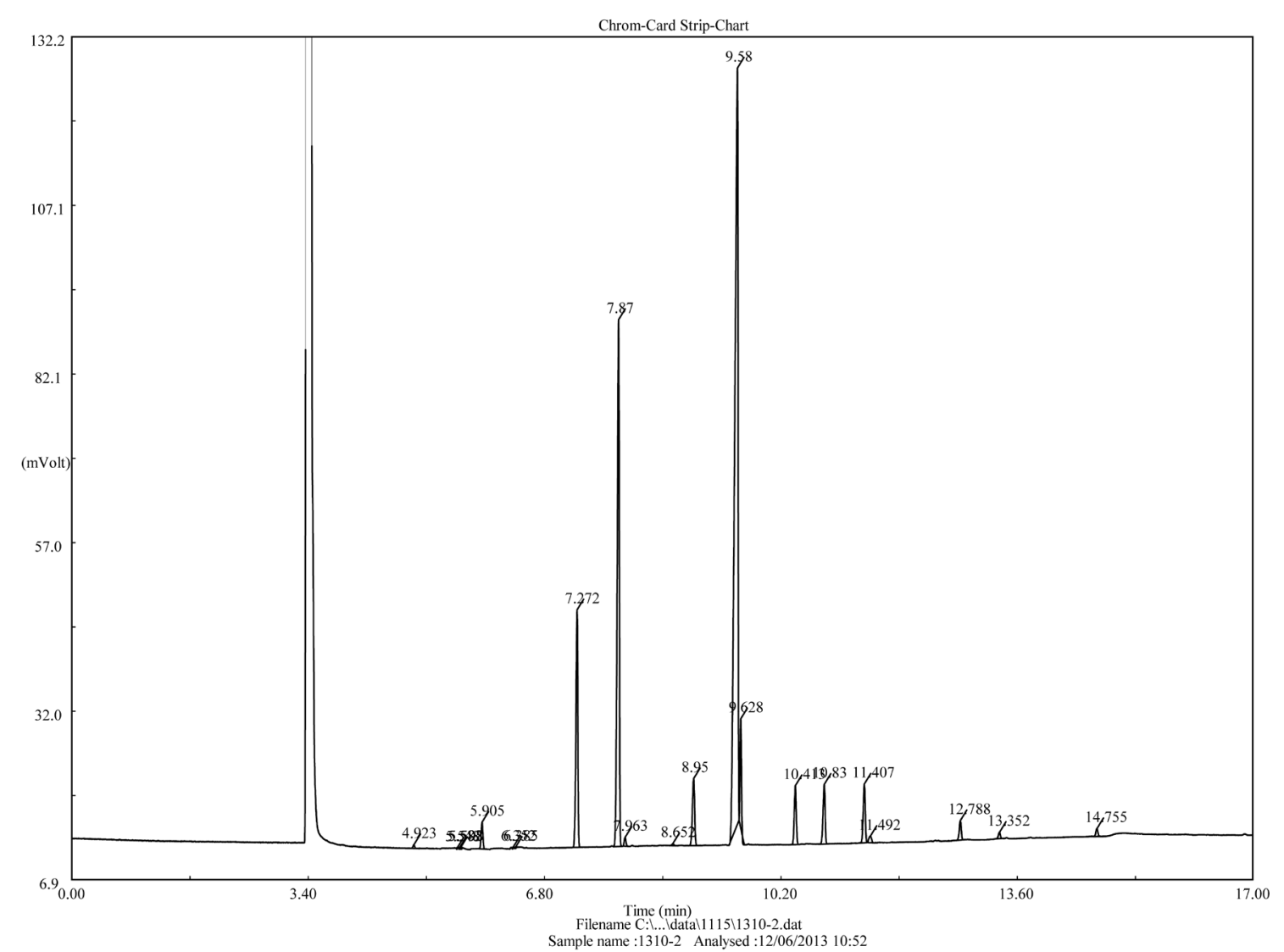

Figure 2. Detection of fatty acid profile of Macadamia integrifolia oil determined by CG.

Polyunsaturated fatty acids (PUFAs) are classified in function of the position of their last double bond at the methyl end of the molecule. According to this, n-3 and n-6 PUFAs (2.4\%, respectively) were are present in Macadamia oil (Table 2). The majority of fatty acids can be synthesized by mammals from the carbohydrates in the diet, but two of these: linoleic acid (LA, 18:2 n-6) and alpha-linolenic acid (LNA, 18:3 n-3) cannot be synthesized endogenously. These are nonetheless necessary as precursors of the long-chain PUFAs and for the proper functioning of the organism [32]. Both $\omega-6$ and $\omega-3$ polyunsaturated fatty acids help to prevent diseases of the circulatory system, as they significantly reduce the levels of total cholesterol and low-density lipoproteins in plasma [33].

The sum of MUFAs and PUFAs represented more than $80 \%$ of the total fatty acids in the sample (Table 3). It is worth noting the presence of trans-vaccenic acid (C 18:1 n-7; 3\% of total fatty acids) in macadamia nuts cultivated in Venezuela. Vaccenic acid (from the Latin vacca (cow)) is an omega-7, naturally occurring trans-fatty acid found in the milk of ruminants and milk products and has also been found in small concentrations in human milk [34] [35]. Its IUPAC name is 11-octadecenoic, and its lipid shorthand name is 18:1 trans-11 [36]. Trans fatty acids are generally considered to have a negative effect on human health, vaccenic acid is not harmful; on the contrary some authors found apparently positive effects. Lock et al. [37] indicated that a number of components of milk fat have anti-carcinogenic properties including conjugated linoleic acid and vaccenic acid. Moreover, trans vaccenic acid is of great interest due to its bioconversion to conjugated linoleic acid by $\Delta 9$ desaturase. This bioconversion, characteristic of ruminants, also occurs in the tissues of non-ruminant animals and humans [34] [38] [39]. In the macadamia nuts here assessed, only $16.5 \%$ of the total fatty acids were saturated, with palmitic acid being the most abundant (9.4\%) (Table 2).

Palmitic acid enriches the phospholipids of cell membranes, interfering with the normal function of low density lipoprotein receptors, reducing their absorption and thus increasing their concentration in the plasma. Kaijser et al. [25] reported that mono-unsaturated fatty acids represent $80 \%$ of the total fats in macadamia nut oil whereas saturated fatty acids were only found in a range from $13.2 \%$ to $17 \%$. The content of polyunsaturated 
fatty acids $(18: 2+18: 3)$ is relatively low, ranging from $2.8 \%$ to $4.7 \%$. These data are comparable with other reports in the literature [40] [41]. Despite this, it is important to consider that the fatty acid composition may vary substantially between different cultivars [25] and among season.

Macadamia integrifolia nut oil has a similar percentage of unsaturated fatty acids to canola oil (80.7\%), peanut oil (85.2\%) and corn oil (82.0\%), and a higher percentage than olive oil (78\%), linseed oil (56\%), soya oil (79\%) and cottonseed oil (72.7\%) [42].

The percentage of specific fatty acids in macadamia nut oil is high compared to many other oils: linolenic acid (C: $18: 3)$ : sunflower oil ( $0.93 \%)$, olive oil $(0.60 \%)$, almond oil $(0.93 \%)$, and maize oil $(1.10 \%)$; oleic acid (C: 18:1): sunflower oil (21.3\%), soya oil (21.1\%), cottonseed oil (33.1\%), maize oil (25.8\%) and sesame oil (45,4\%); stearic acid (C:18): sunflower oil (1.3\%), canola oil (1.5\%), cottonseed oil (1.9\%) and maize oil (1.7\%); palmitic acid (c:16): sunflower oil (6.4\%), canola oil (3.75\%) and sesame oil (9.1\%) and palmitoleic acid (C: 16:1); canola oil (0.25\%) [42].

\subsection{Determination of the Glyceride Profile by TLC}

Thin layer chromatography revealed the presence of triacylglycerides in high concentrations (top band) (Figure 3). Low concentrations of monoacylglycerides (MGs) were observed in the bottom band, higher concentrations of diacylglycerides DG1-2 and DG1-3 (middle bands) as shown by the intensity of the grey color, and finally, as expected, no unlinked fatty acids were found in the sample. It means that this oil was of good quality and that no unspecified lipase was found to be responsible of the enzymatic hydrolysis resulting in the production of DG1-3 and 1-2 [43]. No oxidation bands were observed, showing that oxidative rancidity did not occur.

\subsection{Determination of Tocopherols and Tocotrienols}

No tocopherols or tocotrienols were found in the sample (Figure 4). These results are consistent with Kornsteiner et al. [44] who also registered the absence of tocopherols and tocotrienols in macadamia nuts. However, other studies have indicated that they may be present in very small amounts from 0.6 to $2.8 \mu \mathrm{g} / \mathrm{g}$ [25] [45] [46]. The quality of the nut oil and its stability depends on handling practices during cultivation and harvesting, and the methods used in processing, packaging and storage. The type of packaging used is especially important as it can act as an effective barrier to some of the factors involved in the process of oxidation and loss of quality, such as light, oxygen and humidity [47].

\subsection{Evaluation of Antioxidant Activity}

The sample obtained was analyzed for $30 \mathrm{~min}$ and $60 \mathrm{~min}$. A reduction of $44.2 \%$ of DPPH was observed (Figure 5), which translated a power of slowing or preventing the oxidative stress. Loor and Mino [48], found that at 30 min of analysis, macadamia nut extracts showed inhibition percentages between $45.7 \%$ and $93.9 \%$, demonstrating that some samples may show up to a total reduction of DPPH.

\subsection{Determination of Squalene}

Squalene was detected in the analyzed samples (first bands of Figure 6), but not quantified. Squalene, is a hypo-
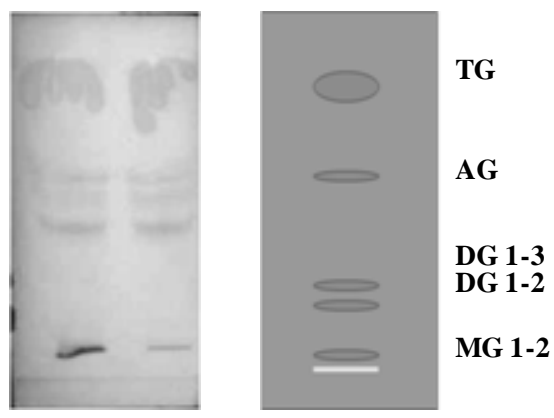

Figure 3. Lipid types in Macadamia integrifolia oil determined by thin layer chromatography. 


\section{Area \% Report m}

Page 1 of $1(6)$

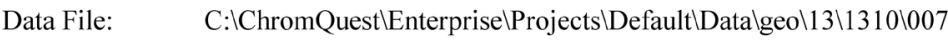

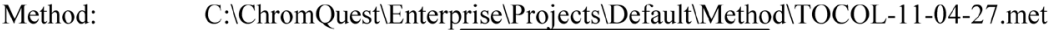

1 Acquired: $\quad$ 11/06/2013 17:44:12

eLIPrinted: $\quad$ 12/06/2013 15:23:00

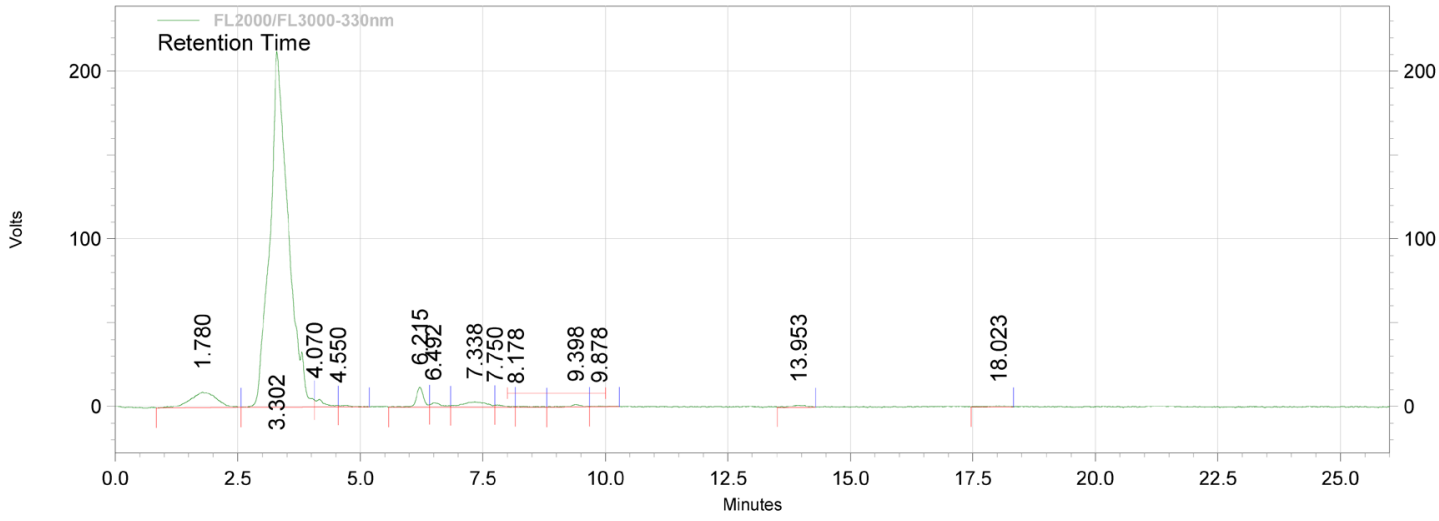

FL2000/FL3000-33

Onm Results

(System

$(12 / 06 / 2013$

15:22:59)

(Reprocessed))

Retention Time

Area

Pk \# Name

ESTD

\begin{tabular}{rrrr} 
& & & concentration \\
\hline 1.78 & 355220 & $\mathbf{1}$ & $\mathbf{0 . 0 0}$ \\
4.30 & 5558618 & $\mathbf{2}$ & $\mathbf{0 . 0 0}$ \\
4.55 & 69290 & $\mathbf{3}$ & $\mathbf{0 . 0 0}$ \\
6.21 & 24002 & $\mathbf{4}$ & $\mathbf{0 . 0 0}$ \\
6.49 & 127057 & $\mathbf{5}$ & $\mathbf{0 . 0 0}$ \\
7.34 & 44337 & $\mathbf{6}$ & $\mathbf{0 . 0 0}$ \\
7.75 & 120426 & $\mathbf{7}$ & $\mathbf{0 . 0 0}$ \\
8.18 & 20953 & $\mathbf{8}$ & $\mathbf{0 . 0 0}$ \\
9.40 & 11694 & $\mathbf{9}$ & $\mathbf{0 . 0 0}$ \\
9.88 & 30738 & $\mathbf{1 0}$ alpha & $\mathbf{0 . 1 4}$ \\
13.95 & 12501 & $\mathbf{1 1}$ & $\mathbf{0 . 0 0}$ \\
18.02 & 33008 & $\mathbf{1 2}$ & $\mathbf{0 . 0 0}$ \\
& 20243 & $\mathbf{1 3}$ & $\mathbf{0 . 0 0}$
\end{tabular}

Figure 4. Detection of tocopherols and tocotrienols by HPLC, in Macadamia integrifolia oil.

cholesterolemic triterpene found in the unsaponifiable material of seed oils and animal fats. This phytochemical is a precursor of cholesterol and other sterols to which antioxidant and cardio protective properties have been attributed, since it may reduce esterified cholesterol, by the oxidation of low density lipoproteins (LDLs) in the blood [49].

\section{Conclusions}

The specified gravity and refractive index values found in the Macadamia integrifolia oil were close to those shown by Macadamia tetraphylla. These indices could be taken as identity criterion for the Macadamia oil. This nut oil shown also is a non-drying oil with a iodine index below 100; which is predicting a low percentage of polyunsaturated fatty acids; as is shown in the saturation profile. However the total of MUFAs and PUFAs was 


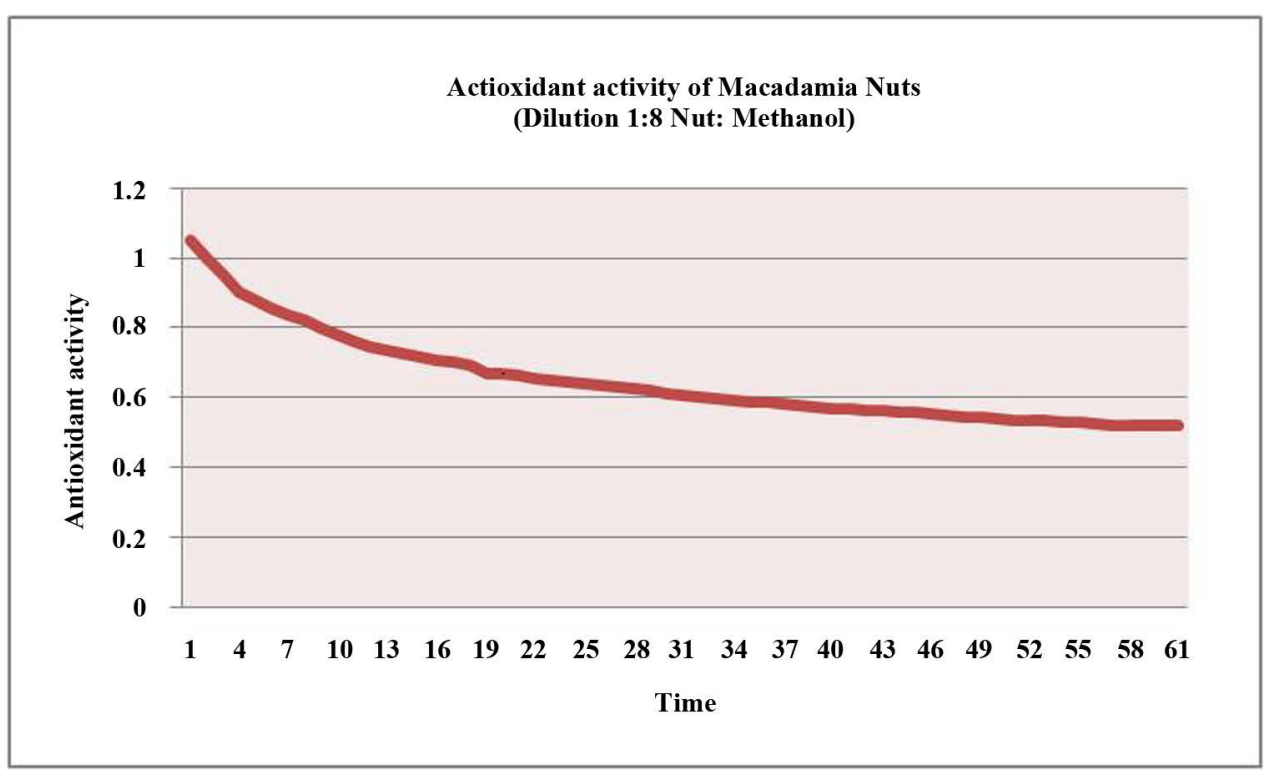

Figure 5. Antioxidant capacity of Macadamia integrifolia oil. (Dilution 1:8 nuts:methanol). X axis: Time, Y axis: Antioxidant capacity.

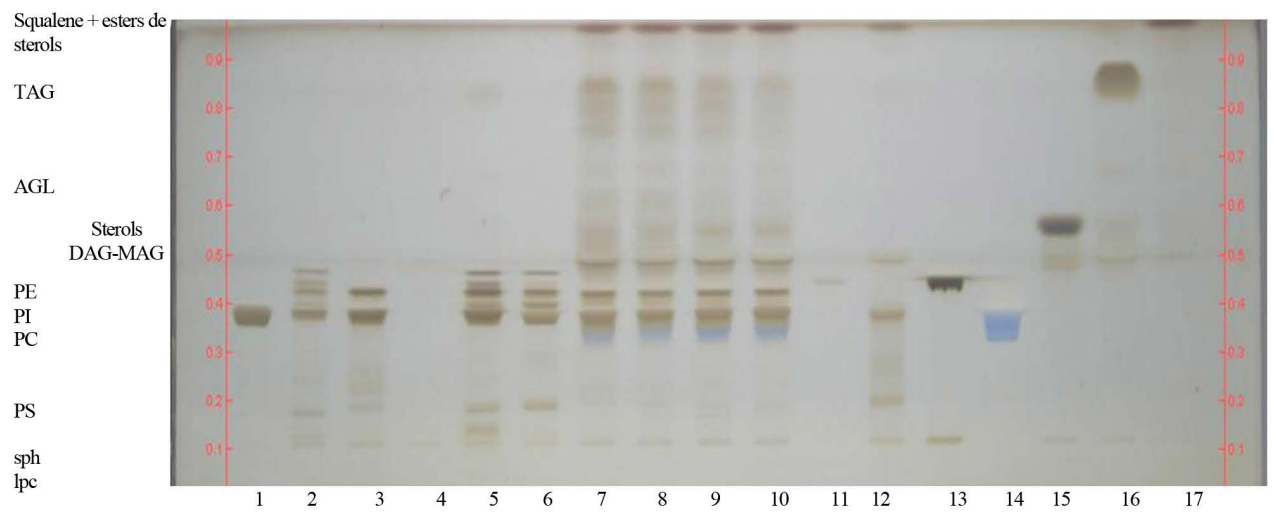

Figure 6. Detection of squalene by thin layer chromatography in Macadamia integrifolia oil.

above the $80 \%$ of the total fatty acids, with the oleic and palmitoleic acids, as the main MUFAs. The Trans-vaccenic acid was also found. Specifically we identified monounsaturated and polyunsaturated fatty acids as well as squalene molecules. We found bioactive compounds in lipids isolated from the Macadamia integrifolia oil from the nuts grown and processed in Venezuela. Samples were also found to show antioxidant activity, which could protect organisms from free radicals, and thus play an important role in the prevention of cancer, inflammatory activity and cardiovascular diseases. No tocopherol or tocotrienols were detected.

\section{Acknowledgements}

The authors are grateful to the National Fund for Science and Technology (FONACIT) for financing the project (PCP No. 2012000001). We are also grateful for the support given by CIRAD and we appreciate the training period of the principal author in Montpellier, France.

\section{References}

[1] Vadivel, V., Kunyanga, C. and Biesalski, H. (2012) Health Benefits of Nut Consumption with Special Reference to Body Weight Control. Nutrition, 28, 1089-1097. http://dx.doi.org/10.1016/j.nut.2012.01.004

[2] Mc Gee, H. (2007) The Kitchen and the Food. Encyclopedia of the Science and the Culture of the Food. Debate 
Publishers, 941.

[3] Sabate, J. and Ang, Y. (2009) Nuts and Health Outcomes: New Epidemiologic Evidence. American Journal of Clinical Nutrition, 89, 1643S-1648S. http://dx.doi.org/10.3945/ajcn.2009.26736Q

[4] De Lira-García, C., Bacardí-Gascón, M. and Jiménez-Cruz, A. (2012) Effect of the Consumption of Nuts, Seeds and Oils on Biochemical Scoreboards and the Corporal Weight: Systematic Review. Hospitable Nutrition, 27, 4.

[5] Australian Macadamia Society (2010) Industry information \& news: Statistics. AMS, Lismore.

[6] Montoya, F. (2012) Commercialization of the Nut of Macadamia for the Strengthening of the Endogenous Development in Villanueva's Community of the Condition Lara. In: Memories of 1er Venezuelan Congress of Science and Technology and Innovation Locti-PEII 1:238. http://www.oncti.gob.ve/

[7] Venkatachalam, M. and Sathe, S.K. (2006) Chemical Composition of Selected Edible Nut Seeds. Journal of Agricultural and Food Chemistry, 54, 4705-4714. http://dx.doi.org/10.1021/jf0606959

[8] INN (2000) National Institute of Nutrition. Table of Food Composition for Practical Use. Publication $\mathrm{N}^{\circ}$ 5, Series of Blue Notebooks, Caracas, 74.

[9] Kris-Etherton, P., Yu-Poth, S., Sabate, J., Ratcliffe, H., Zhao, G. and Etherton, T. (1999) Nuts and Their Bioactive Constituents: Effects on Serum Lipids and Other Factors That Affect Disease Risk. The American Journal of Clinical Nutrition, 70, 504S-511S.

[10] Maguire, L., O’Sullivan, S., Galvin, K., O’Connor, T. and O’Brien, N. (2004) Fatty Acid Profile, Tocopherol, Squalene and Phytosterol Content of Walnuts, Almonds, Peanuts, Hazelnuts and the Macadamia Nut. International Journal of Food Sciences and Nutrition, 55, 171-178. http://dx.doi.org/10.1080/09637480410001725175

[11] Latimer Jr., G., Ed. (2012) Official Methods of Analysis of the AOAC International. 19th Edition, AOAC.

[12] Canning, S., Fazio, P., Fisher, D., Gutman, E., Hsia, C., Kauffma, S., Kramer, J., Lane, M., Leinweber, C. and McGee, P., ASTM (1991) Methods of the American Society for Testing and Material, Method D 369, D 445 and D 801; 168-173, 1-4, 134-136.

[13] Cocks, L. and Van Rede, C. (1997) Laboratory Handbook for Oil and Fat Analysis. Academic Press, London/New York, 30-37.

[14] AOCS (1996) Official Methods and Recommended Practices of the American Oil Chemist’s Society. 5th Edition, Champaign.

[15] Singhal, R. and Kulkarni, P. (1990) Effect of Puffing on Oil Characteristics of Amaranth (Rajgeera) Seeds. Journal of the American Oil Chemists' Society, 67, 952-954. http://dx.doi.org/10.1007/BF02541855

[16] French Norm ISO 5509 (1977) Oily Bodies of Animal and Vegetable Origin, Preparation of Methylic of Oily Acids (index of classification: T60-233 of May 23, 1997).

[17] ISO 5508 (2000) Animal and Vegetable Fats and Oils-Analysis by Gas Chromatography of Methyl Esters of Fatty Acids. International Organization for Standardization, Geneva, Switzerland.

[18] Tuckey, R. and Stevenson, P. (1985) Purification and Analysis of Phospholipids in the Inner Mitochondrial Membrane Fraction of Bovine Corpus Luteum, and Properties of Cytochrome P-450scc Incorporated into Vesicles Prepared from These Phospholipids. European Journal of Biochemistry, 148, 379-384. http://dx.doi.org/10.1111/j.1432-1033.1985.tb08849.x

[19] ISO-FDIS 9936 (1997) Oils and Fats of Animal and Vegetable Origin. Determination of the Content of Tocoferol and Tocotrienol by Means of Chromatography It Liquidates of High Resolution. Final Project of International Norm.

[20] Brand-Williams, W., Cuvelier, M. and Berset, C. (1995) Use of a Free Radical Method to Evaluate Antioxidant Activity. LWT-Food Science and Technology, 28, 25-30. http://dx.doi.org/10.1016/S0023-6438(95)80008-5

[21] Amaral, J., Casal, S., Pereira, J., Seabra, R. and Oliveira, B. (2003) Determination of Sterol and Fatty Acid Compositions, Oxidative Stability, and Nutritional Value of Six Walnut (Juglans regia L.) Cultivars Grown in Portugal. Journal of Agricultural and Food Chemistry, 51, 7698-7702. http://dx.doi.org/10.1021/jf030451d

[22] Miraliakbari, H. and Shahidi, F. (2008) Antioxidant Activity of Minor Components of Tree Nut Oils. Food Chemistry, 111, 421-427. http://dx.doi.org/10.1016/j.foodchem.2008.04.008

[23] Miraliakbari, H. and Shahidi, F. (2008) Oxidative Stability of Tree Nut Oils. Journal of Agricultural and Food Chemistry, 56, 4751-4759. http://dx.doi.org/10.1021/jf8000982

[24] Chunhieng, T., Goli, T., Piombo, G., Pioch, D., Brochier, J. and Montet, D. (2004) Recent Analysis on the Composition of Brazil Nut Bertholletia excelsa. Bois et Forêts des Tropiques, 280, 91-98.

[25] Kaijser, A., Dutta, P. and Savage, G. (2000) Oxidative Stability and Lipid Composition of Macadamia Nuts Grown in New Zealand. Food Chemistry, 71, 67-70. http://dx.doi.org/10.1016/S0308-8146(00)00132-1

[26] Koaze, H., Ndaka, D., Karanja, P., Ishibashi, K.-I. and Baba, N. (2002) Changes in Quality of Dried Macadamia Nuts 
during a Peak Harvest Season in Kenya. Food Science and Technology Research, 8, 32-35.

[27] Carvajal, J. and Bedoya, D. (2010) Physicochemical Study and of Stability of the Oil of Nut of Macadamia tetraphylla Cultivated in the Coffee Colombian Region. Thesis of Degree. Technological University of Pereira, Colombia.

[28] Winston, W. and Shaw, L. (1943) The Process of Oil Formation and Accumulation in Macadamia. Plant Physiology, 18, 1-7. http://dx.doi.org/10.1104/pp.18.1.1

[29] Weston, F. and Fryer, P. (1920) Technical Handbook of Oils Fats and Waxes. In: Abbott, P., Ed., The Cambridge Technical Series, The Cambridge Technical Series, University Press Publishers, England, 120 p. https://books.google.co.ve/books?id=uRNaAAAAYAAJ\&q=weston+fryer+1920\&dq=weston+fryer+1920\&hl=es-419 \&sa=X\&ved=0CBoQ6AEwAGoVChMI2tb388aVyQIVg-8mCh38ZgWY

[30] Mehran, M. (1974) Oil Characteristics of Iranian Walnuts. Journal of the American Oil Chemists Society, 51, 477-478. http://dx.doi.org/10.1007/BF02635854

[31] Farràs, M., Valls, R., Fernández-Castillejo, S., Giralt, M., Solà, R., Subirana, I., Motilva, M.-J., Konstantinidou, V., Covas, M.-I. and Fito, M. (2013) Olive Oil Polyphenols Enhance the Expression of Cholesterol Efflux Related Genes in Vivo in Humans. A Randomized Controlled Trial. The Journal of Nutritional Biochemistry, 24, 1334-1339. http://dx.doi.org/10.1016/j.jnutbio.2012.10.008

[32] Spector, A. (1999) Essentiality of Fatty Acids. Lipids, 34, S1-S3. http://dx.doi.org/10.1007/BF02562220

[33] Castro-Bolaños, M., Herrera-Ramírez, C. and Lutz-Cruz, G. (2005) Composition, Characterization and Potential Aterogénico of Oils, Fats and Other Derivatives Produced or Commercialized in Costa Rica. Costa Rican Medical Record, 47, 1 .

[34] Mosley, E., McGuire, M.K., Willimans, J. and McGuire, M.A. (2006) Cis-9, Trans-11 Conjugated Linoleic Acid Is Synthesized from Vaccenic Acid in Lactating Women. Journal of Nutrition, 136, 2297-2301.

[35] Dreiucker, J. and Vetter, W. (2011) Fatty Acids Patterns in Camel, Moose, Cow and Human Milk as Determined with GC/MS after Silver Ion Solid Phase Extraction. Food Chemistry, 126, 762-771. http://dx.doi.org/10.1016/j.foodchem.2010.11.061

[36] Jutzeler van Wijlena, R. and Colombani, P. (2010) Grass-Based Ruminant Production Methods and Human Bioconversion of Vaccenic Acid with Estimations of Maximal Dietary Intake of Conjugated Linoleic Acids. International Dairy Journal, 20, 433-448. http://dx.doi.org/10.1016/j.idairyj.2010.01.008

[37] Lock, A., Corl, B., Barbano, D., Barman, D. and Clement, I. (2004) The Anticarcinogenic Effect of Trans-11 18:1 Is Dependent on Its Conversion to Cis-9, Trans-11 CLA by $\Delta 9$ Desaturase in Rats. Journal of Nutrition, 134, 2698-2704.

[38] Salminen, I., Mutanen, M., Jauhiainen, M. and Aro, A. (1998) Dietary Trans Fatty Acids Increase Conjugated Linoleic Acids Levels in Human Serum. The Journal of Nutritional Biochemistry, 9, 93-98. http://dx.doi.org/10.1016/S0955-2863(97)00173-3

[39] Turpeinen, A., Mutanen, M. and Aro, A. (2002) Bioconversion of Vaccenic Acid to Conjugated Linoleic Acid in Humans1-3. The American Journal of Clinical Nutrition, 76, 504-10.

[40] Dawson, C. and Savage, G. (1997) Fatty Acid Content of New Zealand Grown Macadamia Nuts. In: O’Connor, J. and Lai, D.T., Eds., Proceedings of the International Conference on Plant Oils and Marine Lipids, Auckland, 25-28 November 1997, 1-183.

[41] Mason, R. and McConachie, I. (1994) A Hard Nut to Crack. Food Australia, 46, 466-471.

[42] Limachi, I., Farfan, O., Sterner, O. and Gimenez, A. (2009) Preliminary Studies of the Chemical Characterization of Fatty Acids of the Oil of Fruits of Bertholletia excelsa by Gas Chromatography. BIOFARBO, 7, 1.

[43] Alencar, E., Faroni, L., Peternelli, L., da Silva, M. and Costa, A. (2010) Influence of Soybean Storage Conditions on Crude Oil Quality. Revista Brasileira de Engenharia Agrícola e Ambiental, 14, 303-308. http://dx.doi.org/10.1590/S1415-43662010000300010

[44] Kornsteiner, M., Wagner, K. and Elmadfa, I. (2006) Tocopherols and Total Phenolics in 10 Different Nut Types. Food Chemistry, 98, 381-387. http://dx.doi.org/10.1016/j.foodchem.2005.07.033

[45] Wall, M. (2010) Functional Lipid Characteristics, Oxidative Stability, and Antioxidant Activity of Macadamia Nut (Macadamia integrifolia) Cultivars. Food Chemistry, 121, 1103-1108. http://dx.doi.org/10.1016/j.foodchem.2010.01.057

[46] Franke, A., Murphy, S., Lacey, R. and Custer, L. (2007) Tocopherol and Tocotrienol Levels of Foods Consumed in Hawaii. Journal of Agricultural and Food Chemistry, 55, 769-778. http://dx.doi.org/10.1021/jf0623844

[47] Oro, T., Ogliari, P., Castanho, R., Barrera-Arellano, D. and Mara, J. (2008) Evaluation of the Quality during the Storage of Nuts Pecán (Carya illinoinensis (Wangenh.) C. Koch) Conditioned in Different Packings. Fats and Oils, 59, 132-138.

[48] Loor, R. and Miño, N. (2012) Determination of the Antirust Capacity of the Nuez of Macadamia by Means of the Me- 
thod DPPH, Obtaining of His Oil Applying the Technology Soxhlet and His Applications in the Food and Cosmetic Products. Thesis of Degree, University of Guayaquil, Ecuador, 143.

[49] Sabeena, F., Anandan, R., Senthil, K., Shiny, S., Sankar, S. and Thankappan, T. (2004) Effect of Squalene on Tissue Defense System in Isoproterenol-Induced Myocardial Infarction in Rats. Pharmacological Research, 50, 231-236. http://dx.doi.org/10.1016/j.phrs.2004.03.004

[50] Jurado, J. and Muñoz, L. (2009) Caracterización del aceite de las semillas de Solanum quitoense L variedad la selva y evaluación de su actividad antioxidante. Thesis of Degree, Technological University of Pereira, Colombia.

[51] Mujica, V., Delgado, M., Ramírez, M., Velásquez, I., Pérez, C. and Rodríguez-Corella, M. (2010) Formulación de un producto cosmético con propiedades antiarrugas a partir del aceite de merey (Anacardium occidentale L). Revista de la Facultad de Ingeniería de la Universidad Central de Venezuela, 25, 2.

[52] Codexstan 33 (1989) Norma del Codex para los aceites de olive virgin y refinados y los aceites refinados de orujo. Rev 1989.

[53] Bailey, A. (1951) Industrial Oil and Fat Products. Interscience Publishers, New York, 967 p. 